\title{
Erratum to: Social Thinking®: Science, Pseudoscience, or Antiscience?
}

\author{
Justin B. Leaf ${ }^{1}$ - Alyne Kassardjian ${ }^{1}$ • Misty L. Oppenheim-Leaf ${ }^{2} \cdot$ Joseph H. Cihon $^{1}$ • \\ Mitchell Taubman $^{1} \cdot$ Ronald Leaf $^{1} \cdot$ John McEachin ${ }^{1}$
}

Published online: 28 March 2016

(C) Association for Behavior Analysis International 2016

\section{Erratum to: Behav Analysis Practice DOI 10.1007/s40617-016-0108-1}

In our recent published discussion article (Leaf et al., 2016), we referred to the Behavior Analyst Certification Board ${ }^{\mathbb{R}}$ 's $\left(\mathrm{BACB}^{\circledR}\right)$ ethics code and disciplinary system in relation to certified behavior analysts who would implement, recommend, or endorse Social Thinking ${ }^{\circledR}$. Below is the paragraph that was written in the original manuscript:

Behaviorists should not engage in procedures during clinical practice that would be considered pseudoscience or anti-science, as doing so can cause harm to an individual diagnosed with ASD and their family. Additionally, doing so would not align with a behaviorist's training. As such, both certified and non-certified behavior analysts should not implement, recommend, or endorse Social Thinking ${ }^{\circledR}$; doing so would violate the ethical guidelines described by the $\mathrm{BACB}^{\circledR}$ (BACB 2015; retrieved from: http://www.bacb.com/index.php?page=57). The ethical

The online version of the original article can be found at http://dx.doi.org/ 10.1007/s40617-016-0108-1.

Justin B. Leaf

Jblautpar@aol.com

Alyne Kassardjian

Akautpar@aol.com

Misty L. Oppenheim-Leaf

Molbtlc@aol.com

Joseph H. Cihon

Jcihonautpar@aol.com

Mitchell Taubman

Mtautpar@aol.com standards of BACB state that behavior analysts have to design behavior change programs that are consistent with behavior analytic principles and indicate that endorsement of Social Thinking ${ }^{\circledR}$ would be a violation of a client's rights to effective treatment (BACB 2015; retrieved from: http://www.bacb.com/index.php? page = 57). These violations could result in disciplinary action against a certified behavior analyst."

However, the paragraph should have read as follows:

Behaviorists should not engage in procedures during clinical practice that would be considered pseudoscience or anti-science, as doing so can cause harm to an individual diagnosed with ASD and their family. Additionally, doing so would not align with a behaviorist's training. As such, both certified and non-certified behavior analysts should carefully consider the evidence base reviewed here before implementing, recommending, or endorsing Social Thinking ${ }^{\circledR}$. Our conclusion is that Social Thinking ${ }^{\circledR}$ is

Ronald Leaf

Rlautpar@aol.com

John McEachin

Jmautpar@aol.com

1 Autism Partnership Foundation, 200 Marina Drive, Seal Beach, CA 90740, USA

2 Behavior Therapy and Learning Center, 200 Marina Drive, Seal Beach, CA 90740, USA 
not consistent with behavior-analytic principles. Therefore, we believe it falls within the definition of "non-behavior-analytic" interventions as described in Section 8.01 of the BACB ${ }^{\circledR}$ Professional and Ethical Compliance Code for Behavior Analysts (BACB, 2016; retrieved from: http://bacb.com/ethics-code). The ethics code of the BACB requires use of the following written disclaimer on all names and descriptions of non-behavioranalytic interventions: "These interventions are not behavior-analytic in nature and are not covered by my BACB credential.” (BACB, p. 16).
Compliance and Ethical Standards This erratum does not include any human or animal participants. There are no conflicts of interest for this erratum across all authors.

\section{Reference}

Leaf, J. B., Kassardjian, A., Oppenheim-Leaf, M. L., Cihon, J. H., Taubman, M., Leaf, R., et al. (2016). Social thinking ${ }^{\mathbb{R}}$ : science, pseudoscience, or antiscience? Behavior Analysis in Practice. doi: 10.1007/s40617-016-0108-1. 